\title{
$\mathrm{SOHO}$ 환경을 위한 효율적인 VoIP 단말 관리 기법 설계 및 구현
}

\author{
진 상 우 $^{+}$경 계 현 $^{++} \cdot$ 고 광 선 $^{+++} \cdot$ 엄 영 익 $^{++++}$
}

요 약

\begin{abstract}
인터넷 전화는 $\mathrm{VoIP}$ 를 이용하는 전화 방식으로서 VoIP 단말이 인터넷에 연결되어 있다면 저렴한 요금과 다양한 부가서비스가 가능한 방식 이다. 하지만 인터넷 전화를 관리하기 위한 시스템들은 대규모의 VoIP 서비스 사업자들이나 대기업에서의 사용을 목적으로 하여 개발되어 오 면서 설치 및 관리의 편의성 부분이 결여되어 있으며, 이러한 문제점들은 $\mathrm{VoIP}$ 단말 설치를 어렵게 하여 인터넷 전화 보급에 장애가 되어 왔 다. 본 논문에서는 이러한 문제를 해결하고자 $\mathrm{VoIP}$ 단말들의 설정 관리를 목적으로 하는 자동 프로비저닝 시스템을 설계하고 구현한다. 이 시 스템은 $\mathrm{SOHO}$ 환경과 같이 소규모 $\mathrm{VoIP}$ 환경에서 $\mathrm{VoIP}$ 단말들을 쉽게 설치하고 관리할 수 있도록 지원한다.
\end{abstract}

키워드 : 인터넷 전화, VolP, Auto provisioning

\section{Design and Implementation of an Efficient Management Scheme for VoIP Terminals in SOHO Environments}

\author{
Sangwoo $\mathrm{Jin}^{\dagger} \cdot$ Gye-hyeon Gyeong ${ }^{+\dagger} \cdot$ Kwang Sun $\mathrm{Ko}^{++\dagger} \cdot$ Young $\mathrm{Ik} \mathrm{Eom}^{++\dagger+}$
}

\begin{abstract}
Internet telephone uses VoIP as its communication protocol, where it provides various additional services with inexpensive fare when the terminal is connected to the Internet. The existing auto provisioning systems that manage Internet telephone terminals are targeting large size VoIP service providers or enterprises, and has few consideration on the convenience of management for small size environments. The difficult installation and management procedures of the current auto provisioning systems prevents Internet telephone system from getting popular. Easy installation and management system is needed in order to spread out Internet telephone system. In this paper, we design and implement the auto provisioning system that provides easy installation and management services in small size environments such as $\mathrm{SOHO}$ environments.
\end{abstract}

Key Words : Internet telephone, VolP, Auto provisioning

\section{1. 서 론}

VoIP란 지금까지 PSTN 네트워크를 통해 이루어졌던 음 성 서비스를 인터넷 프로토콜(IP)을 이용하여 음성 서비스 를 지원하며, 추가적으로 여러 가지 다양한 서비스를 제공 하는 기술을 말한다. 이렇게 인터넷망을 이용함으로써 인터 넷 전화는 전 세계 어디서나 저렴한 가격으로 통화할 수 있 는 기능을 지원하며, 이를 기반으로 기존의 전화망에서 하 지 못했던 많은 서비스들을 지원한다. 대표적인 응용들로서 는 웹콜센터, Instant messaging, CTI(computer Telephony

\footnotetext{
† 정 회 원 : 성균관대학교 이동통신공학과 석사과정

†† 준 회 원: 성균관대학교 전자전기컴퓨터공학과 석사과정

휘 정 회 원 : 성균관대학교 이동통신공학과 연구교수

†+† 종신회원: 성균관대학교 정보통신공학부 교수

논문접수:2007년 11월 26일, 심사완료 : 2008년 2월 23일
}

Integration), UMS(Unified Messaging System) 등을 들 수 있으며, 현재도 다양한 서비스들이 개발되고 있다. 인터넷 전화를 사용하기 위해서는 VoIP 단말의 설치와 인터넷 전 화를 사용하기 위한 설정을 수행해야만 한다. 이러한 불편 함을 해결하기 위해, 네트워크 관리 시스템의 기능 중에서 $\mathrm{VoIP}$ 단말 설정 관리 기능만 특화된 자동 프로비저닝 시스 템(auto provisioning system)이 도입되었다. 하지만 자동 프로비저닝 시스템의 수요처가 VoIP 서비스 사업자들이나 대기업으로 한정 되어 있으며 이러한 이유로 기존의 자동 프로비저닝 시스템들은 일반적으로 VoIP 서비스 사업자들 이나 대기업에서의 사용을 대상으로 하여 개발되어 왔다. 이러한 시스템들은 편의성이 배제되어 있기 때문에 전문적 지식을 갖춘 관리자만이 관리할 수 있으며, 이러한 이유로 
일반인들은 설치와 관리가 어려워 인터넷 전화의 대중화를 막는 원인이 되고 있다.

기존의 자동 프로지저닝 시스템들은 HTTP [1] 서버나 TFTP [2] 서버를 이용해서 VoIP 단말들의 설정 데이터를 내려 받을 수 있도록 해주는 방식과 Cisco의 CallManager [3]라는 제품과 같이 이런 설정 데이터를 관리할 수 있는 부 가 기능을 가지고 있는 방식이 주로 사용되어져 왔다.

본 논문에서는 $\mathrm{SOHO}$ 환경과 같은 소규모 환경에서도 별 도의 관리자 없이 $\mathrm{VoIP}$ 단말의 설치 및 관리를 자동으로 수행해 주는 IP-PBX를 이용한 자동 프로비저닝 시스템을 설계한다. $\mathrm{SOHO}$ 용 $\mathrm{IP}-\mathrm{PBX}$ 에 자동 프로비저닝 시스템을 추가한 서버를 구축하며, 이를 통하여 $\mathrm{VoIP}$ 단말들은 설치 와 관리가 자동으로 이루어질 수 있다. 이러한 시스템은 전 문적인 네트워크 관리자나 인터넷 전화 관리 전문가가 없는 소규모 환경에서도 VoIP 단말의 설치와 관리를 쉽게 수행 할 수 있는 장점을 지니고 있다.

\section{2. 자동 프로비저닝 기법}

자동 프로비저닝 시스템은 $\mathrm{VoIP}$ 단말들의 설정 관리를 목적으로 하는 시스템이다. 본 절에서는 $\mathrm{VoIP}$ 환경에서 사 용되는 자동 프로비저닝 기법 두 가지를 소개한다.

\subsection{HTTP/TFTP 서버를 이용한 자동 프로비저닝 기법}

일반적으로 VoIP 단말들은 HTTP 서버나 TFTP 서버로 부터 자신의 설정 데이터를 내려 받아서 사용할 수 있는 기 능을 가지고 있다. HTTP 서버나 TFTP 서버의 디렉토리에 각 $\mathrm{VoIP}$ 단말별 설정 데이터를 파일로 만들어서 저장해 놓 으면 VoIP 단말은 부팅시에 자동 프로비저닝을 통하여 자 동으로 설정을 수행하게 된다.

하지만 이렇게 설정데이터를 파일로 관리하는 방식은 일 반적으로 관리에 어려움이 많게 된다. 파일의 이름은 $\mathrm{VoIP}$ 단말의 $\mathrm{MAC}$ 주소를 사용하여 정해야 하며, $\mathrm{VoIP}$ 단말에는 $\mathrm{HTTP}$ 서버나 TFTP 서버의 주소를 설정해 놓거나 $\mathrm{DHCP}$ [4] 서버로 받을 수 있도록 구성되어 있어야만 한다.

\section{$2.2 \mathrm{Cisco}$ 사의 자동 프로비저닝 기법}

Cisco에서는 IP-PBX기능을 수행하는 CallManager를 이 용하여 자동 프로비저닝 기법을 제공하고 있다. CallManager는 음성 통화 제어와 음성 응용 기능들을 제공 하는 장비로서 이 장비의 단말인 $\mathrm{VoIP}$ 단말에 대한 관리 기능을 제공하고 있다. 먼저 CallManager는 등록된 $\mathrm{VoIP}$ 단말의 설정을 암호화한 후 $\mathrm{VoIP}$ 단말의 $\mathrm{MAC}$ 주소로 이름 을 지정하여 파일로 저장하여 관리한다. $\mathrm{VoIP}$ 단말이 설정 파일을 요구하면 CallManager는 TFTP 프로토콜을 이용하 여 그 파일을 $\mathrm{VoIP}$ 단말에게 전달하게 된다. 또한 $\mathrm{VoIP}$ 단 말이 재설정이 필요할 시 CallManager는 $\mathrm{VoIP}$ 단말에게 리 셋을 시킬 수 있는 메시지를 보낼 수 있으며, 리셋 메시지 를 받은 $\mathrm{VoIP}$ 단말은 리셋 작업을 수행한다. 하지만 $\mathrm{VoIP}$
단말에 기본적인 네트워크 설정이나 서버에 대한 정보를 사 용자가 직접 입력해야 하고, 각 $\mathrm{VoIP}$ 단말별 개별 관리가 어려운 단점이 있다.

\section{3. $\mathrm{SOHO}$ 환경을 위한 자동 프로비저닝 시스템 설계}

현재 IP-PBX와 VoIP 단말을 설치하고 사용함에 있어서 가장 많이 제기되고 있는 문제점들은 다음과 같다.

- 설치의 어려움 및 반복적으로 해야 하는 $\mathrm{VoIP}$ 단말 설정의 필요성

- 자동 프로비저닝 시스템을 사용하는 경우에도 $\mathrm{VoIP}$ 단 말에 기본적인 네트워크에 관련된 정보와 자동 프로비저 닝 시스템이 구축된 서버에 대한 정보의 설정의 필요성

위의 문제를 해결하기 위하여 본 논문에서는 관리자 또는 사용자에 의한 각각의 $\mathrm{VoIP}$ 단말 설정을 하지 않고도 자동 프로비저닝 서버(자동 프로비저닝 시스템이 구축된 서버)를 통하여 자동으로 구성되게 하는 S-APS(Auto Provisioning System for $\mathrm{SOHO}$ )를 설계하고자 한다. S-APS는 관리자가 존재하지 않는 $\mathrm{SOHO}$ 환경과 같이 $5 \sim 50$ 개 정도의 $\mathrm{VoIP}$ 단 말을 사용하는 환경에서 유용하게 사용될 수 있다. S-APS 가 적용된 $\mathrm{VoIP}$ 환경에서는 $\mathrm{VoIP}$ 단말의 $\mathrm{S}-\mathrm{APS}$ 서버 검 색방법, $\mathrm{S}-\mathrm{APS}$ 로 부터의 $\mathrm{VoIP}$ 단말 자동 설정 방법, $\mathrm{S}-\mathrm{APS}$ 의 설정 내용 변경 시 $\mathrm{VoIP}$ 단말의 적용 방법으로 이루어진 세 가지 메커니즘이 필요하다.

\subsection{VolP 단말의 S-APS 검색 방법}

$\mathrm{VoIP}$ 단말이 $\mathrm{S}-\mathrm{APS}$ 와 연동하기 위해 필요한 기본적인 정보들의 획득을 자동화 한다. 이를 위하여 다음과 같은 특 징을 지니고 있는 $\mathrm{mDNS}$ [5]/DNS-SD [6] 프로토콜을 적용 한다.

- 멀티캐스트 방식을 사용하여 서버에 대한 정보가 없어 도 자동으로 서버를 찾을 수 있음

- $\mathrm{DNS}$ 를 이용하여 서비스를 검색하는 기능을 제공함

$\mathrm{VoIP}$ 단말은 $\mathrm{mDNS} / \mathrm{DNS}-\mathrm{SD}$ 프로토콜을 이용하여 (그 림 1)에서 보이는 것과 같은 절차에 따라 S-APS 서버를 검 색하고 S-APS 서버로부터 정보를 받아 네트워크를 설정할 수 있다.

(그림 1)에서 보이는 바와 같이, 먼저 $\mathrm{VOIP}$ 단말은 멀티 캐스트 DNS-SD 쿼리를 이용하여 S-APS 서버에 네트워크 설정 정보를 요청해야 한다. 통신을 위해서는 IP 주소가 필 요하며, VoIP 단말은 주소 생성을 위해 IPv6 프로토콜의 비 상태 주소 자동설정(Stateless address autoconfiguration)기 법을 사용한다 [7]. 이 기법은 추가적인 장치나 사용자에 의 한 설정이 없이도 단말 스스로 주소를 생성하여 통신을 수 


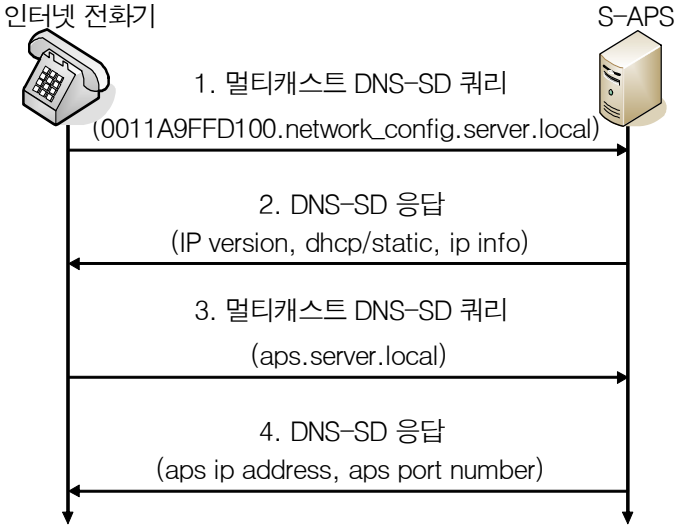

(그림 1) $\mathrm{mDNS} / \mathrm{DNS}-\mathrm{SD}$ 를 이용한 S-APS 검색 및 네트워 크 설정

행할 수 있는 주소 생성 기법이다. 이렇게 생성된 주소는 Link-local 주소로서 동일한 링크에서만 통신이 가능하므로, $\mathrm{VoIP}$ 단말을 사용하기 위해서는 다음 단계에서 S-APS 서 버로부터 전송되는 주소 정보를 이용하여 IP 주소를 새롭게 설정해야 한다.

\section{- $<$ VoIP 단말의 MAC 주소>.network_config.server.local}

멀티캐스트 DNS-SD 쿼리는 기본적으로 $\mathrm{DNS}$ 쿼리 형식 을 취해야 하며, 위와 같은 형식으로 도메인 이름에 $\mathrm{VoIP}$ 단말의 $\mathrm{MAC}$ 주소를 포함하도록 한다. S-APS 서버에서는 이러한 쿼리를 받으면 $\mathrm{MAC}$ 주소를 이용하여 해당 $\mathrm{VoIP}$ 단 말의 설정 데이터를 검색할 수 있다. S-APS 서버는 VoIP 단말의 네트워크 설정을 위하여 다음과 같은 정보를 포함하 여 전송한다.

- IP 프로토콜 버전

- IP 설정 방식 $(\mathrm{DHCP} / \mathrm{Static})$ 의 선택

- IP 설정 방식이 static일 경우 static IP 주소의 정보

이 정보들은 DNS TXT Resource Record 방식 [8]을 사 용하여 에 전송되며, $\mathrm{VoIP}$ 단말은 S-APS 서버로부터 받은 네트워크 설정 정보를 이용하여 네트워크 설정을 수행한다. VoIP 단말은 다시 멀티캐스트 DNS-SD 쿼리를 이용하여 S-APS 서버의 주소와 포트 번호를 요청한다. 이 경우의 도 메인 이름은 서버의 주소와 포트 번호를 얻기 위한 방법인 DNS SRV [9]에 따라서_aps._tcp.server.local와 같은 형식 으로 도메인을 구성한다.

이러한 방식은 $\mathrm{VoIP}$ 단말가 동일 링크에서만 사용할 수 있는 Link-local 주소를 사용하기 때문에 S-APS 서버가 동 일한 링크에 있어야만 사용 가능하다는 제약이 있다. 이러 한 경우에는 S-APS Relay를 이용하여 해결할 수 있다. S-APS Relay는 VoIP 단말로부터의 $\mathrm{mDNS} / \mathrm{DNS}-\mathrm{SD}$ 요청 을 수신하고, 이를 유니캐스트 DNS-SD로 변환하여 S-APS
서버로 전달하는 역할을 수행한다. 그리고 S-APS 서버로부 터 응답이 오면, 이를 다시 VoIP 단말로 전달한다. 이러한 방식은 $\mathrm{VoIP}$ 단말들이 S-APS 서버와 동일 링크에 존재하 는 것과 같은 환경을 만들어준다.

\subsection{S-APS로 부터의 VolP 단말 자동 설정 방법}

다음으로 $\mathrm{VoIP}$ 단말은 $\mathrm{S}-\mathrm{APS}$ 에서 정보를 받아 $\mathrm{VoIP}$ 단 말에 $\mathrm{VoIP}$ 를 위한 설정을 자동으로 수행한다. 이 과정에서 $\mathrm{S}-\mathrm{APS}$ 에서는 $\mathrm{VoIP}$ 단말의 설정 데이터들을 관리하기 위하 여 프로파일 항목을 사용한다. 프로파일은 설정 내용 중 동 일한 부분을 하나의 그룹으로 묶어 관리할 데이터의 양을 최소화 하는데 목적을 갖으며, 아래와 같은 내용으로 프로 파일이 구성된다.

- $\mathrm{VoIP}$ 패킷 처리를 위한 IP-PBX의 주소

- SIP 프로토콜에 대한 설정 값

설정 정보를 요청하고 받기 위해서 $\mathrm{VoIP}$ 단말은 네트워 크 설정단계에서 얻은 S-APS의 IP 주소와 포트번호를 이 용하여 S-APS에게 연결한다. 이때 VoIP 단말은 HTTPS [10] 프로토콜을 사용하여 VoIP 단말의 설정 데이터들을 다 운로드 한다. VoIP 단말은 HTTPS의 URL로서 MAC 주소 를 사용하며, $\mathrm{S}-\mathrm{APS}$ 는 $\mathrm{MAC}$ 주소를 이용하여 설정 정보를 검색하고 이 정보를 $\mathrm{VoIP}$ 단말에 전송한다.

$3.3 \mathrm{~S}-\mathrm{APS}$ 의 설정 내용 변경 시 $\mathrm{VoIP}$ 단말의 적용 방법 마지막으로 $\mathrm{S}-\mathrm{APS}$ 에 등록된 설정 내용의 변경 시 변경 내용을 $\mathrm{VoIP}$ 단말에 자동으로 적용할 수 있도록 한다. $\mathrm{S}-\mathrm{APS}$ 에 $\mathrm{VoIP}$ 단말이 등록된 후 사용자가 $\mathrm{VoIP}$ 단말을 사용 중에 있을 때, $\mathrm{S}-\mathrm{APS}$ 에서 $\mathrm{VoIP}$ 단말의 설정을 수정 하는 경우의 처리 방법은 $\mathrm{S}-\mathrm{APS}$ 에서 $\mathrm{VoIP}$ 단말에 변경된 설정이 있다는 이벤트를 전송하는 방법을 사용한다. 이를 위하여 S-APS는 다음과 같은 내용을 수행 할 수 있도록 설계되어야 한다.

- VoIP 단말 등록정보를 이용하여 VoIP 단말들의 주소 를 추적하고 있어야 함

- $\mathrm{VoIP}$ 단말의 설정 값이 수정되는 경우에는 $\mathrm{VoIP}$ 단 말로 이벤트를 전송해야 함

이벤트를 전송하기 위해서 $\mathrm{IP}-\mathrm{PBX}$ 에서 $\mathrm{VoIP}$ 를 위하여 사용되고 있는 SIP의 Notify Request를 이용한다. VoIP 단 말이 설정 변경 Notify Request를 수신하게 되면, S-APS에 연결하여 3.2 장의 방법에 따라서 설정 데이터들을 다운로드 하여 재 적용하게 된다. 그리고 설정 변경뿐 아니라 $\mathrm{VoIP}$ 단말의 소프트웨어가 업그레이드 된 경우에도 SIP [11] 프 로토콜의 Notify Request를 사용하여 VoIP 단말에게 소프트 웨어가 업그레이드되었음을 알려주고, 업그레이드를 수행할 시간을 예약하여, VoIP 단말이 추후에 소프트웨어를 업그레 이드 할 수 있도록 한다. 


\section{S-APS의 구현}

본 장에서는 앞서 설명한 앞서 설명한 세 가지 메커니즘 의 동작을 위하여 VoIP 단말, S-APS relay, S-APS 서버에 필요한 부분을 구성하고, 각 구성별로 자세한 설명을 한다.

\section{1 장비별 구조도}

(그림 2)에서 보이는 바와 같이 S-APS를 이용하는 인터 넷 전화 환경은 $\mathrm{APS}$ 서버, $\mathrm{APS}$ Relay, 그리고 $\mathrm{VoIP}$ 단말 로 구성되며, 각 부분의 역할은 <표 $1>$ 에서 자세히 설명하 고 있다.

(그림 2)에서 보이는 바와 같이, VoIP 단말에는 설치와 설 정에 관련된 구성요소들이 추가로 구현되었다. 구성요소들은 $\mathrm{S}-\mathrm{APS}$ 서버를 찾고 네트워크 설정을 위한 $\mathrm{mDNS} / \mathrm{DNS}-\mathrm{SD}$ Client, S-APS 서버로부터 설정 정보를 전달받는 APS Client, 받아온 설정 정보를 이용하여 $\mathrm{VoIP}$ 단말에 설정작업을 수행하 는 Configuration Manager, SIP User Agent로 구성된다.

$\mathrm{S}-\mathrm{APS}$ 서버는 IP-PBX내부에 추가되므로 $\mathrm{IP}-\mathrm{PBX}$ 가 $\mathrm{S}-\mathrm{APS}$ 서버 역할을 동시에 수행하게 된다. 앞 절에서 언급한 기능들을 구현하기 위하여 SIP PBX Daemon, HTTP Daemon, Auto provisioning Daemon, mDNS/DNS-SD Daemon, S-APS Database, DNS-SD Database들이 서로 상 관관계를 갖고 동작하게 된다.

S-APS Relay의 기본 구조는 VoIP 단말의 구조와 동일하 다. 단지 S-APS Relay를 추가하여 같은 네트워크에 있는 다 른 $\mathrm{VoIP}$ 단말들이 $\mathrm{S}-\mathrm{APS}$ 와 같은 네트워크에 있는 것과 동일 한 효과를 나타낸다. 이를 위해서 $\mathrm{mDNS} / \mathrm{DNS}-\mathrm{SD}$ Relay는 $\mathrm{mDNS}$ 서버로서 동작을 하도록 구성된다. $\mathrm{mDNS} / \mathrm{DNS}-\mathrm{SD}$ Relay는 VoIP 단말들로부터 멀티캐스티 DNS-SD 쿼리를 받 게 되면 이를 유니캐스트 DNS-SD 쿼리로 변환하여 S-APS 서버로 전달한다. 그리고 S-APS 서버로부터 DNS-SD 응답 을 받아서 멀티캐스트 DNS-SD 쿼리를 보낸 VoIP 단말로 다 시 전달해주는 역할을 한다. 이런 S-APS 서버와의 통신을 위 해서 $\mathrm{mDNS} / \mathrm{DNS}-\mathrm{SD}$ Client에 유니캐스트 DNS-SD 쿼리를 전송할 수 있는 기능이 추가 된다.

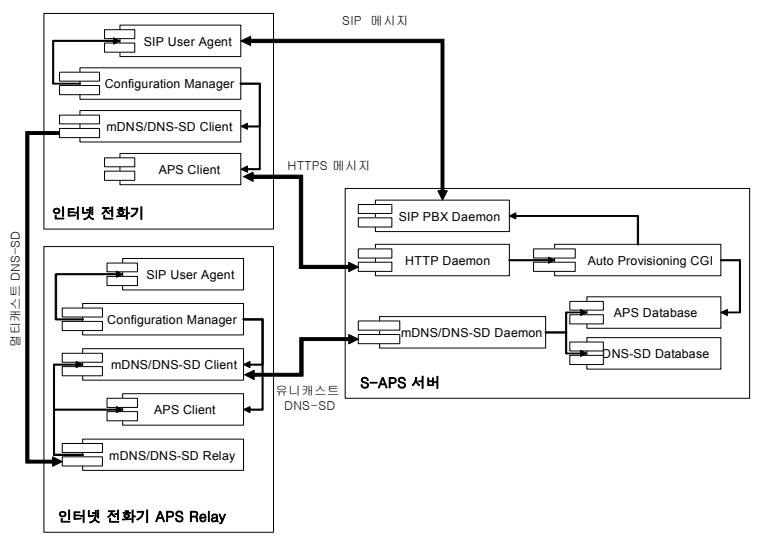

(그림 2) S-APS 구성요소 구조도
〈표 1〉VoIP 단말과 S-APS 관련 구성요소

\begin{tabular}{|c|c|c|}
\hline \multicolumn{2}{|c|}{ 구성요소 } & 역할 \\
\hline \multirow{4}{*}{ VoIP 단말 } & $\begin{array}{l}\mathrm{SIP} \text { 사용자 } \\
\text { 에이전트 } \\
\text { (SIP User } \\
\text { Agent) }\end{array}$ & $\begin{array}{l}\cdot \mathrm{SIP} \text { 프로토콜을 처리함 } \\
\cdot \mathrm{SIP} \text { 호에 대한 처리와 SIP Notify 요 } \\
\text { 청으로 S-APS 서버로부터 VoIP 단말 } \\
\text { 에 전달되는 S-APS 관련 통지를 구성 } \\
\text { 요소들에게 전달하는 역할을 수행함 }\end{array}$ \\
\hline & $\begin{array}{l}\text { 설정 매니저 } \\
\text { (Configuration } \\
\text { Manager) }\end{array}$ & $\begin{array}{l}\mathrm{VoIP} \text { 단말에 저장되어 있거나 } \mathrm{S}-\mathrm{APS} \\
\text { 서버로부터 받은 설정 데이터를 이용 } \\
\text { 하여, } \mathrm{VoIP} \text { 단말의 각 } \mathrm{S} / \mathrm{W} \text { 구성요소 } \\
\text { 및 } \mathrm{H} / \mathrm{W} \text { 의 초기화 역할을 수행함 } \\
\text { - 각 단계 별로 필요한 데이터를 구하 } \\
\text { 기 위하여 } \mathrm{mDNS} / \mathrm{DNS}-\mathrm{SD} \text { Client와 } \\
\text { APS Client를 사용함 }\end{array}$ \\
\hline & $\begin{array}{l}\mathrm{mDNS} / \mathrm{DNS}-\mathrm{S} \\
\mathrm{D} \text { 클라이언트 } \\
(\mathrm{mDNS} / \mathrm{DNS}- \\
\mathrm{SD} \text { Client) }\end{array}$ & $\begin{array}{l}\text { - 멀티캐스트 DNS-SD 쿼리를 전송하 } \\
\text { 고, DNS-SD 응답을 수신함 } \\
\text { - 네트워크 설정에 대한 데이터와 S-APS } \\
\text { 서버의 주소와 포트번호를 구함 }\end{array}$ \\
\hline & $\begin{array}{l}\text { S-APS } \\
\text { 클라이언트 } \\
\text { (S-APS } \\
\text { Client) }\end{array}$ & $\begin{array}{l}\cdot \mathrm{HTTPS} \text { 프로토콜을 사용하여 S-APS } \\
\text { 서버로부터 VoIP 단말의 설정 데이터 } \\
\text { 를 내려 받는 역할을 수행함 } \\
\cdot \mathrm{MAC} \text { 주소를 매개변수로 하는 } \\
\mathrm{HTTP} \text { Get 요청이 사용됨 } \\
\text { - S-APS 서버로부터 내려 받는 설정 } \\
\text { 데이터를 파싱하여 VoIP 단말에서 } \\
\text { 사용할 수 있는 형식으로 변환함 }\end{array}$ \\
\hline \multirow{6}{*}{$\begin{array}{l}\mathrm{S}-\mathrm{APS} \\
\text { 서버 }\end{array}$} & $\begin{array}{l}\text { SIP PBX 데몬 } \\
\text { (SIP PBX } \\
\text { Daemon) }\end{array}$ & $\begin{array}{l}\cdot \mathrm{SIP} \text { 서버 역할을 하는 프로세스로서 } \\
\text { VoIP 단말들의 SIP 요청을 처리함 } \\
\text { - VoIP 단말로의 호가 발생하는 경우에 } \\
\text { 는 호를 VoIP 단말에게 전달하는 역 } \\
\text { 할을 하는 IP-PBX의 역할을 수행함 } \\
\text { - VoIP 단말들의 SIP 등록 요청을 처 } \\
\text { 리 하며, 이를 통하여 VoIP 단말들 } \\
\text { 의 주소를 실시간으로 관리함 } \\
\text { - 다른 프로세스들에서 VoIP 단말로 } \\
\text { 통지를 하고자 하면, SIP의 Notify } \\
\text { 요청을 사용하여 이를 수행함 } \\
\text { - 사용자의 요청으로 데이터의 수정이 } \\
\text { 발생하게 되는 경우, SIP PBX } \\
\text { Daemon을 통하여 VoIP 단말에게 } \\
\text { 데이터 변경이 발생하였음을 통지 }\end{array}$ \\
\hline & $\begin{array}{l}\text { HTTP 데몬 } \\
\text { (HTTP } \\
\text { Daemon) }\end{array}$ & $\begin{array}{l}\text { - 일반적인 HTTP 프로토콜을 처리하 } \\
\text { 는 프로세스 } \\
\text { - 각 URL별로 파일전송을 수행함 } \\
\text { - 자동 프로비저닝 요청이 들어오면 } \\
\text { Auto provisioning CGI [12]로 전달 }\end{array}$ \\
\hline & $\begin{array}{l}\text { 자동 } \\
\text { 프로비저닝 } \\
\text { CGI } \\
\text { (Auto } \\
\text { provisioning } \\
\text { CGI) }\end{array}$ & $\begin{array}{l}\text { - HTTP Daemon을 통하여 들어오는 } \\
\text { VoIP 단말들의 자동 프로비저닝 요 } \\
\text { 청을 받음 } \\
\text { - VoIP 단말의 MAC 주소를 키로 사 } \\
\text { 용하여, S-APS Database에 저장되 } \\
\text { 어있는 VoIP 단말을 위한 설정 데이 } \\
\text { 터를 VoIP 단말에게 전송함 }\end{array}$ \\
\hline & $\begin{array}{l}\mathrm{mDNS} / \mathrm{DNS}-\mathrm{S} \\
\mathrm{D} \text { 데몬 } \\
\text { (mDNS/DNS- } \\
\text { SD Daemon) }\end{array}$ & $\begin{array}{l}\cdot \mathrm{mDNS} / \mathrm{DNS}-\mathrm{SD} \text { 의 서버 역할을 하는 } \\
\text { 프로세스로서 VoIP 단말들의 멀티캐 } \\
\text { 스트 DNS-SD 쿼리와 S-APS Relay } \\
\text { 의 유니캐스트 DNS-SD 쿼리를 처리. } \\
\cdot \text { VoIP 단말 네트워크 설정 쿼리와 서 } \\
\text { 비스 서버의 주소에 대한 쿼리를 처리 } \\
\text { · 쿼리에 포함된 MAC 주소를 이용하 } \\
\text { 여 DNS-SD 데이터베이스를 검색 }\end{array}$ \\
\hline & $\begin{array}{l}\text { S-APS } \\
\text { 데이터베이스 } \\
\text { (S-APS } \\
\text { Database) }\end{array}$ & $\begin{array}{l}\cdot \mathrm{S}-\mathrm{APS} \text { 에 관계된 데이터들의 관리 } \\
\cdot \mathrm{S}-\mathrm{APS} \text { 데이터의 추가, 수정 그리고 } \\
\text { 검색을 담당 } \\
\cdot \mathrm{S}-\mathrm{APS} \text { 관련 프로세스들의 } \mathrm{APS} \text { 데이 } \\
\text { 터에 대한 요청을 처리 }\end{array}$ \\
\hline & $\begin{array}{l}\text { DNS-SD } \\
\text { 데이터베이스 } \\
\text { (DNS-SD } \\
\text { Database) }\end{array}$ & $\begin{array}{l}\text { - } \mathrm{DNS}-\mathrm{SD} \text { 가 제공할 서비스 서버에 대 } \\
\text { 한 정보에 대한 검색과 관리를 담당 }\end{array}$ \\
\hline
\end{tabular}




\section{2 동작 시나리오}

(그림 3)은 $\mathrm{S}-\mathrm{APS}$ 가 적용된 환경에서 $\mathrm{VoIP}$ 단말들이 관 리되는 한 예를 보이고 있다. (그림 3)에서의 환경은 서로 다른 두 개의 네트워크가 존재하며 한 네트워크에는 S-APS 서버가 존재하며 다른 네트워크에는 존재하지 않는 다. 하지만 S-APS 서버가 존재하지 않는 네트워크에는 릴 레이가 존재하여 S-APS 서버로의 연결을 지원할 수 있다.

(그림 3)에서 보이는 바와 같은 환경에서, S-APS 서버가 존재하는 네트워크에 $\mathrm{VoIP}$ 단말이 새로 설치되면 다음과 같은 과정을 거치게 된다.

- VoIP 단말은 멀티캐스트 DNS-SD 쿼리를 보내어 $\mathrm{S}-\mathrm{APS}$ 서버에 정보를 요청한다.

- S-APS 서버는 VoIP 단말의 쿼리를 받아 VoIP 단말 에 필요한 네트워크 설정 정보와 자동 프로비저닝 서 비스를 제공하는 서버의 주소와 포트번호를 검색한다. 검색된 정보는 쿼리를 보낸 $\mathrm{VoIP}$ 단말에 전송된다.

- $\mathrm{VoIP}$ 단말은 S-APS 서버로부터 받은 정보를 이용하 여 VoIP 단말의 네트워크를 설정하고 서버의 주소와 포트번호를 이용하여 S-APS 서버에 접속한다.

- S-APS 서버는 $\mathrm{VoIP}$ 단말의 프로비저닝 요청을 인식 하고 $\mathrm{VoIP}$ 단말을 설정하기위한 설정 파일들을 HTTPS 프로토콜을 이용하여 VoIP 단말에 전송한다.

$\mathrm{VoIP}$ 단말이 설치되는 네트워크에 S-APS 서버가 없다 하더라도 S-APS Relay가 설치되어 있기 때문에 VoIP 단말 의 설치는 정상적으로 완료될 수 있다. S-APS Relay는 멀 티 캐스트 DNS-SD 쿼리를 유니캐스트 DNS-SD 쿼리로 변환하여 Relay에 지정된 S-APS 서버로 전송하는 역할을

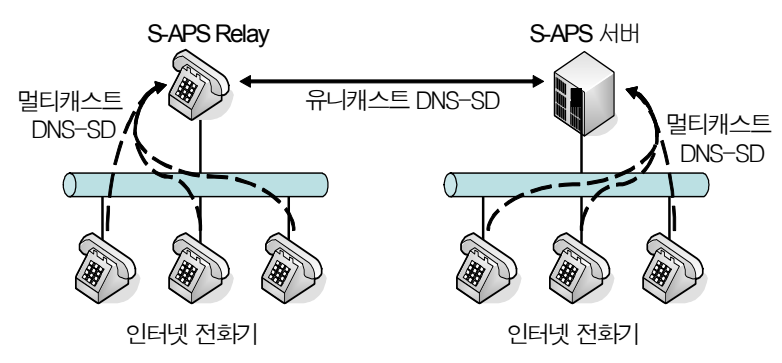

(그림 3) S-APS를 이용한 인터넷 전화 구성도

수행하며 VoIP 단말과 S-APS 서버간의 연결을 중계한다. 이러한 과정을 통하여 $\mathrm{VoIP}$ 단말은 설정 파일들을 내려 받 은 후 $\mathrm{VoIP}$ 단말을 설정하고 이후 사용자는 $\mathrm{VoIP}$ 단말을 이용하여 통화를 할 수 있다. (그림 4)에서 이런 동작을 수 행할 때의 네트웍 요청과 응답을 보여주고 있다.

\section{5. 구현 및 비교}

본 논문에 $\mathrm{S}-\mathrm{APS}$ 의 구현은 임베디드 환경으로의 이식성 을 고려하여 $\mathrm{C} / \mathrm{C}++$ 언어로 구현되었다. $\mathrm{S}-\mathrm{APS}$ 를 위하여 사용되는 네트워크 프로토콜들이 모두 $\mathrm{TCP} / \mathrm{IP}$ 만을 사용하 고 있기에 모든 네트워크 관련 기능들은 표준 socket 함수 들만을 사용하여 구현하였다. 이는 socket 인터페이스를 지 원하는 여러 운영체제로의 이식성을 위한 것이다. S-APS 서버 부분에 있어서 SIP PBX Daemon과 HTTP Daemon은 기존의 IP-PBX에 존재하는 코드를 재사용 했으며, S-APS 관련 부분만 새롭게 구현 하였다. Auto provisioning CGI는 Get 방식의 CGI로서 $\mathrm{C}++$ 를 사용하여 구현하였다. 또한

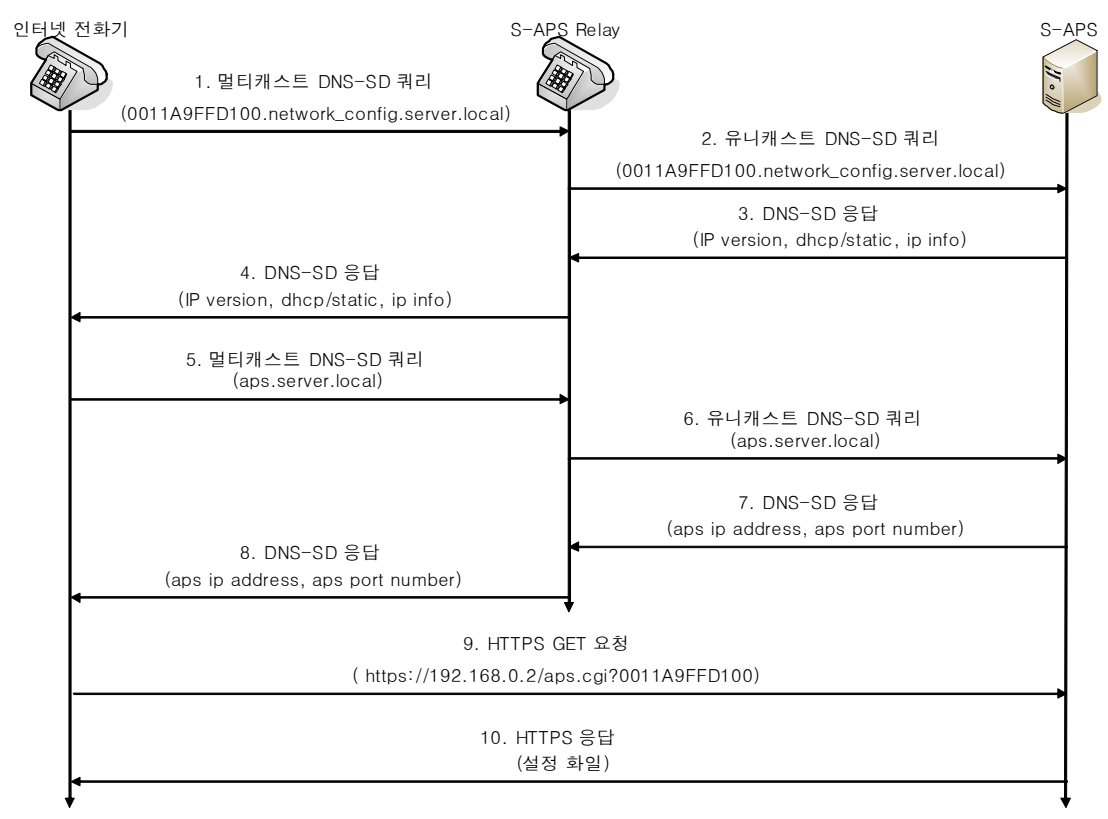

(그림 4) S-APS를 이용한 자동 프로비저닝 네트웍 흐름도 
Multicast DNS를 처리하기 위한 $\mathrm{mDNS} / \mathrm{DNS}-\mathrm{SD}$ Daemon, Relay와 Client는 Open Source인 Avahi Project [13]의 라이 브러리를 사용하여 구현하였다. Avahi는 Linux를 위해 $\mathrm{mDNS} / \mathrm{DNS}-\mathrm{SD}$ 를 구현한 것이다. 이것은 Linux에 종속적 이거나 임베디드 환경에 맞지 않는 부분들이 있기에 $\mathrm{S}-\mathrm{APS}$ 를 위하여 일부 라이브러리만을 추출하여 구현하는 데 사용하였다. Avahi에서 추출한 부분은 표준 socket 인터 페이스의 Multicast 옵션을 사용하여 구현된 Multicast socket 인터페이스 부분과 DNS 패킷을 처리하는 부분이다. $\mathrm{mDNS} / \mathrm{DNS}-\mathrm{SD}$ Client부분과 Relay는 VxWorks라는 상용 임베디드 운영체제를 사용하는 VoIP 단말에서 구현하였다.

(그림 4)에서는 S-APS에서 단말 프로파일을 추가하고 사용자를 추가하는 유저 인터페이스 화면을 보이고 있다.

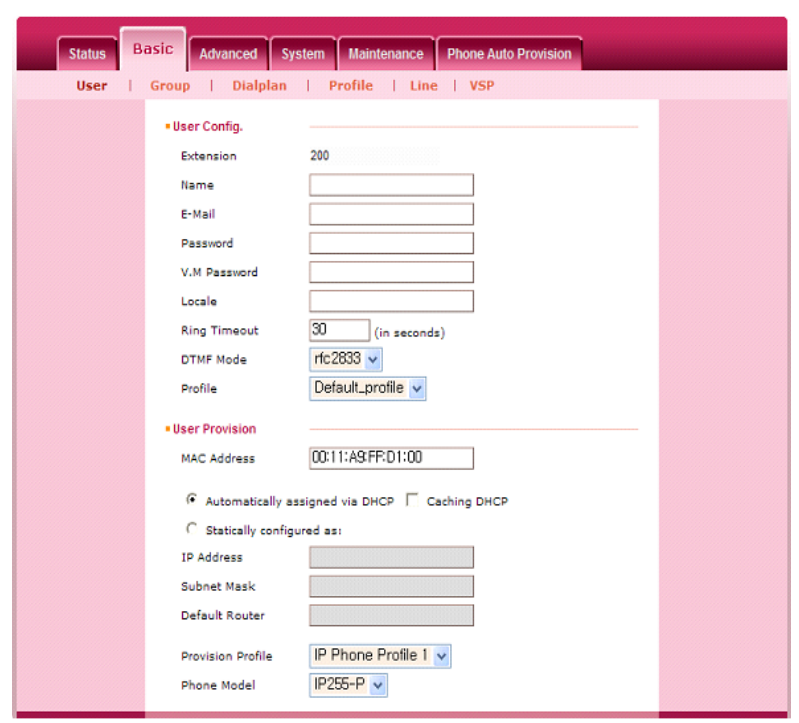

(2) VolP 단말 추가 유저 인터페이스 화면

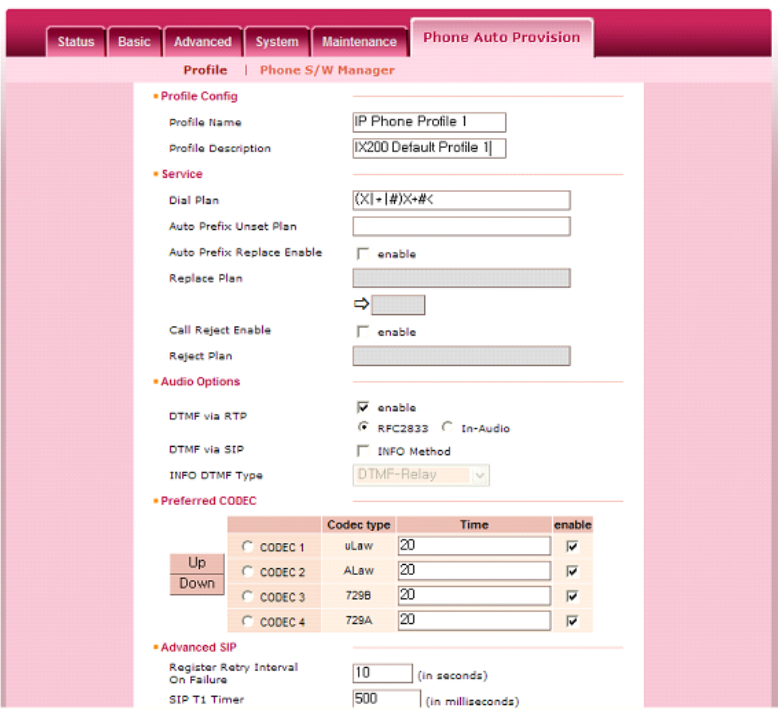

(1) VolP 단말 프로파일 추가 유저 인터페이스 화면

(그림 5) S-APS 유저 인터페이스 화면

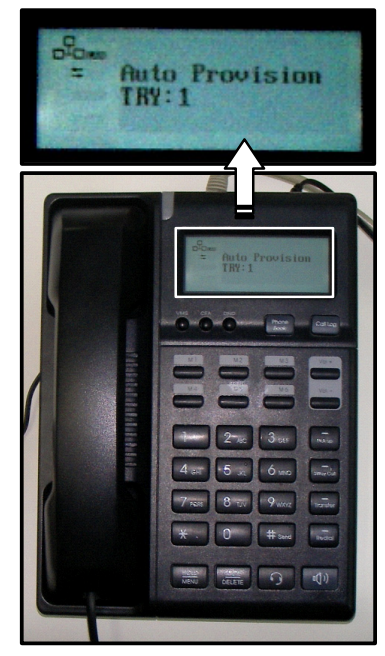

(그림 6) VolP 단말 실행 모습

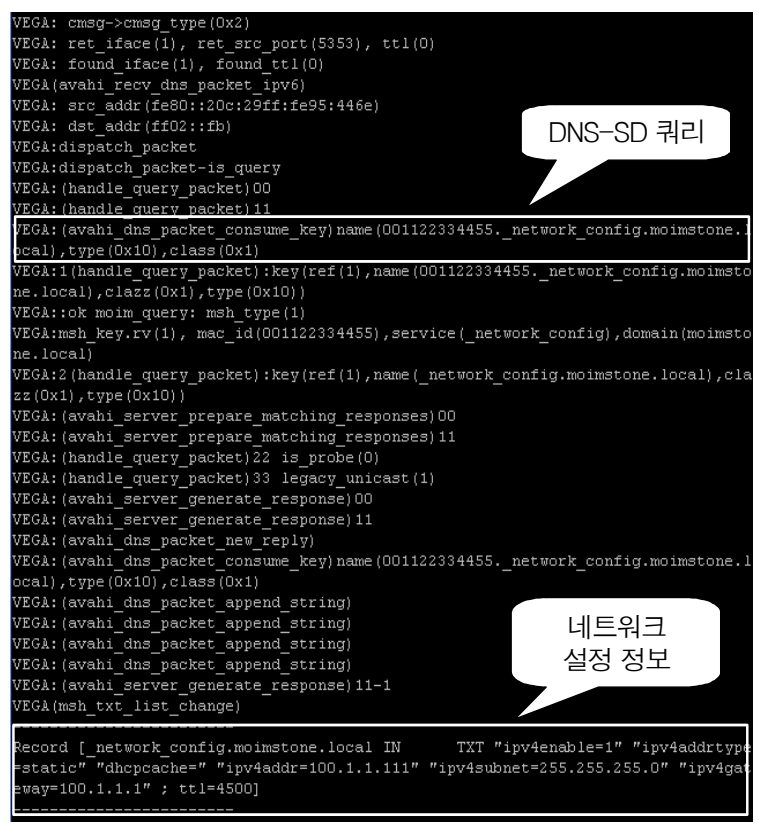

(그림 7) S-APS의 설정 관련 로그

$\mathrm{VoIP}$ 단말의 설정 데이터들에는 많은 항목들이 존재하지만, (그림 4)의 (1)에서 보이는 바와 같이 전화기별로 동일한 내 용은 프로파일로 생성하여 각 단말별 설정에서 발생할 수 있는 반복 작업을 줄일 수 있다. (그림 5)의 (2)는 각 개별 $\mathrm{VoIP}$ 단말들을 설정할 수 있으며 프로파일 내용을 제외한 변경되기 쉬운 정보들만으로 구성되어 있다. 그 외의 정보 들은 Provision Profile 항목을 통해서 설정되어지게 된다. 그리고 Phone Model항목은 VoIP 단말의 하드웨어 정보를 나타내는 것으로 $\mathrm{VoIP}$ 단말의 소프트웨어 자동 업그레이드 를 위하여 사용된다. 이렇게 $\mathrm{S}-\mathrm{APS}$ 에 $\mathrm{VoIP}$ 단말에 대한 설정을 하면, $\mathrm{VoIP}$ 단말 설치 시 자동으로 설정을 수행할 수 있다. (그림 6과 7)은 자동으로 설정되는 모습을 보이고 있다. 
〈표 2〉APS들간의 편의성 관련 비교

\begin{tabular}{|c|c|c|c|}
\hline \multirow{2}{*}{ 항목 } & \multicolumn{2}{|c|}{ 기존 기법 } & 제안 기법 \\
\cline { 2 - 4 } & HTTP/TFTP APS & Cisco CallManager & S-APS \\
\hline \hline VoIP 단말에서의 네트워크 설정 & 필요 & 필요 \\
\hline VoIP 단말에서의 APS 설정 & 불필요 $(*)$ & 불필요 $(*)$ & 불필요 \\
\hline $\mathrm{APS}$ 에서의 VoIP 단말 추가 방법 & 복사 후 수정 & 복사 후 수정 & 프로파일 선택 \\
\hline $\mathrm{APS}$ 에서의 그룹별 수정 기능 & 없음 & 없음 & 있음 \\
\hline $\mathrm{APS}$ 에서의 수정 즉시 적용 기능 & 없음 & 있음 $(* *)$ & 있음 \\
\hline $\mathrm{VoIP}$ 단말 $\mathrm{S} / \mathrm{W}$ 업그레이드 & 단말 개별 지정 & 단말 개별지정 & $\mathrm{H} / \mathrm{W}$ 종류별 지정 \\
\hline
\end{tabular}

* 네트웍 주소 설정을 위해 $\mathrm{DHCP}$ 사용 및 $\mathrm{DHCP}$ 서버에 $\mathrm{APS}$ 에 대한 등록 필요함.

** VoIP 단말을 개별적으로 리셋 시켜서Auto Provisioning을 다시 시도하도록 하는 방식.

〈표 3〉 HTTP APS와 S-APS의 VoIP 단말 설치시의 VoIP 단말과 APS에서의 설정 항목 수 비교

\begin{tabular}{|c|c|c|c|c|}
\hline \multirow{2}{*}{ VoIP 단말 수 } & \multicolumn{2}{|c|}{ HTTP APS } & \multicolumn{2}{c|}{ S-APS } \\
\cline { 2 - 5 } & VoIP 단말 & APS & VoIP 단말 & APS \\
\hline \hline 10 & 30 & 30 & 0 & 60 \\
\hline 20 & 60 & 60 & 0 & 90 \\
\hline 30 & 90 & 90 & 0 & 120 \\
\hline 40 & 120 & 120 & 0 & 150 \\
\hline 50 & 150 & 150 & 0 & 30 \\
\hline
\end{tabular}

(그림 6)은 VoIP 단말 설치 시 단말에 표시되는 화면을 보 이고 있다. $\mathrm{VoIP}$ 단말이 설치가 되면 부팅 과정을 거치면서 자동 프로비저닝 단계를 수행하게 된다. (그림 7)은 $\mathrm{VoIP}$ 단 말의 설치 및 설정에 관한 정보를 배포하는 S-APS에서 $\mathrm{VoIP}$ 단말과 주고받는 정보들에 대한 로그를 보이고 있다. VoIP 단 말의 자동 프로비저닝 단계가 종료되면 인터넷 전화를 사용 할 수 있다. 이러한 방식으로 동작하는 $\mathrm{S}-\mathrm{APS}$ 를 $\mathrm{HTTP} / \mathrm{TFTP}$ 서버를 이용한 APS 방식, Cisco CallManager 방식과 비교하여 보면 <표 2>와 같은 결과를 볼 수 있다.

각 항목을 자세히 살펴보면 먼저 S-APS는 VoIP 단말에 서의 설정이 불필요하다. 기존의 방식들은 $\mathrm{VoIP}$ 단말에 네 트워크 설정이나 APS 서버에 대한 정보를 설정해야만 사용 이 가능하였다. 하지만 S-APS는 VoIP 단말과 같은 단말에 서의 설정이 필요 없도록 하여 관리자의 관리 없이 $\mathrm{VoIP}$ 단말의 설치 및 관리를 자동화 하고 있다.

다음으로 $\mathrm{S}-\mathrm{APS}$ 는 $\mathrm{APS}$ 서버에서의 설정을 최소화 하고 있다. HTTP/TFTP APS와 Cisco의 CallManager에서 새로운 $\mathrm{VoIP}$ 단말을 등록하기 위해서는 등록되어 있는 $\mathrm{VoIP}$ 단말의 설정을 복사한 후에 필요한 부분을 수정하는 방식을 사용한 다. 이 방식은 복사 대상 선정의 오류와 같은 사용자의 실수 가 발생하기 쉽다는 단점이 있고 추후 관리에 있어서는 개별 적인 수정을 필요로 하게 된다. S-APS에서는 프로파일을 선 택하는 설정 방법을 통하여 각 $\mathrm{VoIP}$ 단말의 설정에 필요한
입력 항목의 반복적인 입력을 최소화 하고 있다.

다음으로 변경 사항의 적용 방법을 자동화 하고 있다. APS 에서 VoIP 단말의 설정을 변경하는 경우, HTTP/TFTP APS 같은 경우에는 $\mathrm{VoIP}$ 단말이 주기적으로 $\mathrm{APS}$ 에 접속하여 변 경 여부를 검사하는 방식을 사용하고 있다. 또한 CallManager는 변경 사항을 적용하고자 할 때 사용자가 CallManager를 통하여 VoIP 단말을 리셋 시키는 방식으로 적용을 시키고 있다. 이 방식은 VoIP 단말을 개별적으로 리셋 시켜야 하는 단점이 있다. 본 논문의 S-APS에서는 변경 사항 이 생기면, 이를 VoIP 단말에게 알려주어서 VoIP 단말이 변 경 사항을 즉시 반영할 수 있도록 하고 있다.

마지막으로 $\mathrm{VoIP}$ 단말 소프트웨어 업그레이드 시 하드웨 어별 그룹 관리가 가능하다. 일반적으로 소프트웨어 업그레 이드는 VoIP 단말 전체를 대상으로 하게 된다. 본 논문의 $\mathrm{S}-\mathrm{APS}$ 에서는 VoIP 단말을 하드웨어별로 그룹 지어서 소프 트웨어 업그레이드 할 수 있기 때문에 단말별 개별 관리에 비하여 VoIP 단말 전체를 업그레이드 하는데 필요한 입력 사항을 대폭 줄여줄 수 있다.

다음은 HTTP APS와 S-APS를 사용하여 VoIP 단말의 설치 시에 사용자가 $\mathrm{VoIP}$ 단말과 $\mathrm{APS}$ 에서 수행해야 하는 최소 설정 항목의 개수를 설치해야할 $\mathrm{VoIP}$ 단말의 수를 증 가시켜가며 비교를 하였다.

<표 2>에서 보여 지는 것과 같이 $\mathrm{S}-\mathrm{APS}$ 를 사용하는 경 
우에 있어서는 $\mathrm{VoIP}$ 단말에서의 설정이 필요 없는 관계로 설치 시에 각 단말의 설치가 매우 쉬워 진다는 장점을 제공 할 수 있는 것이다.

\section{6. 결 론}

본 논문에서는 $\mathrm{VoIP}$ 단말의 관리를 목적으로 하는 $\mathrm{S}-\mathrm{APS}$ 의 설계와 구현에 대하여 설명하였다. 본 논문의 $\mathrm{S}-\mathrm{APS}$ 는 $\mathrm{SOHO}$ 환경과 같이 적은 인원으로 운영되고, 네 트워크 전문가가 없는 환경을 대상으로 하는 경우에 최적화 된 서비스 제공을 목적으로 하였다. S-APS는 사용자의 편 의성에 중점을 두고 설계를 하였고 기존의 $\mathrm{APS}$ 들에 비하여 편의성 부분을 크게 개선하였다. 먼저 설치 과정에서 반복 적으로 일어날 수밖에 없는 $\mathrm{VoIP}$ 단말들의 설정에 관련된 작업을 프로파일을 이용함으로써 관리 작업을 단순화 하였 으며, S-APS 검색 방법을 자동화 하여 기존의 VoIP 단말 들의 설치 과정에서 필수적으로 발생하는 관리자에 의한 초 기 설정 작업을 자동화 하였다. 그리고 $\mathrm{APS}$ 에서 $\mathrm{VoIP}$ 단 말의 설정 변경을 그룹으로 적용할 수 있게 하여 사용 중에 발생할 수 있는 설정 변경 작업을 단순화 하였다. S-APS는 $\mathrm{IP}-\mathrm{PBX}$ 와 $\mathrm{VoIP}$ 단말 도입에 방해가 되어 왔던 설치 및 관 리의 복잡함을 개선하여 인터넷 전화의 보급에 도움이 될 것이다.

\section{참 고 문 헌}

[1] R. Fielding, R. Fielding, J. Mogul, H. Frystyk, L. Masinter, P. Leach, and T. Berners-Lee, RFC 2616, Hypertext Transfer Protocol -- HTTP/1.1., Jun. 1999.

[2] K. Sollins, RFC 1350, The TFTP Protocol (Revision 2), Jul. 1992.

[3] Cisco, Cisco Unified CallManager Administration Guide, Release 5.0, Jun. 2006.

[4] R. Droms, RFC 2131, Dynamic Host Configuration Protocol, Mar. 1997.

[5] S. Cheshire and M. Krochmal, Internet-Draft, draft-cheshire-dnsext-multicas- tdns-06, Multicast DNS, Aug. 2006.

[6] S. Cheshire and M. Krochmal, draft-cheshire-dnsext-dns-sd-04, DNS-Based Service Discovery, Aug. 2006.

[7] S. Thomson, T. Narten, and T. Jinmei, RFC 4862, IPv6 Stateless Address Autoconfiguration, Sep. 2007.

[8] P. Mockapetris, RFC 1035, Domain names - implementation and specification, Nov. 1987.

[9] A. Gulbrandsen, P. Vixie, and L. Esibov, RFC 2782, A DNS RR for specifying the location of services (DNS SRV), Feb. 2000.

[10] E. Rescorla, RFC 2818, HTTP Over TLS, May. 2000.

[11] J. Rosenberg, H. Schulzrinne, G. Camarillo, A. Johnston, J. Peterson, R. Sparks, M. Handley, and E. Schooler, RFC 3261, SIP: Session Initiation Protocol, Jun. 2002.

[12] D. Robinson, K. Coar, RFC 3875, The Common Gateway Interface (CGI) Version 1.1, Oct. 2004.

[13] Avahi Project, http://avahi.org

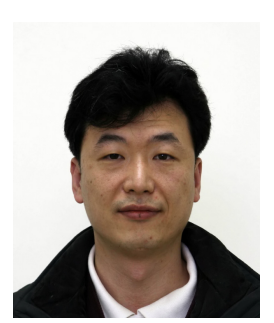

진 상 우

e-mail :swjinjin@paran.com

1998년 성균관대학교 기계공학과 (학사)

1999년 2001년 (주)성운엔지니어링 부설 연구소 주임연구원

2001년 2003년 (주)텔레트론 부설연구소 선임연구원

2003년 현재 (주)모임스톤 부설연구소 책임연구원 2007년 현재 성균관대학교 이동통신공학과 석사과정 관심분야: $\mathrm{VoIP}$, 분산 컴퓨팅, 운영체제, 내장형 시스템 등
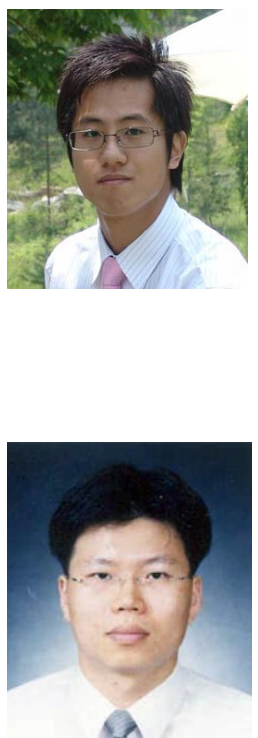

경 계 현

e-mail : gyehyeon@ece.skku.ac.kr 2006년 호서대학교 컴퓨터공학과 (학사) 2006년 현 재 성균관대학교 전자전기 컴퓨터공학과 석사과정 관심분야: 이동 컴퓨팅, 이동 에이전트, 시스템 보안, 분산 컴퓨팅, 운영체제, 내장형 시스템 등

\section{고 광 선}

e-mail : rilla91@ece.skku.ac.kr 1998년 성균관대학교 정보공학과 (학사) 2004년 성균관대학교 전기전자및컴퓨터공학부(공학석사) 2007년 성균관대학교 전자전기컴퓨터공학과(공학박사)

2007년 현 재 성균관대학교 이동통신공학과 연구교수 관심분야: 정보보호, 리눅스, 네트워크 등

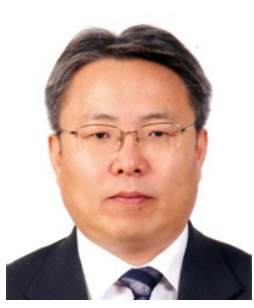

\section{엄 영 익}

e-mail : yieom@ece.skku.ac.kr 1983년 서울대학교 계산통계학과 (학사) 1985년 서울대학교 전산과학과 (이학석사) 1991년 서울대학교 전산과학과 (이학박사) 2000년 2001년 Dept. of Info. and Comm. Science at UCI 방문교수

2005년 한국정보처리학회 학회지 편집위원장 1993년 현 재 성균관대학교 정보통신공학부 교수 관심분야: 분산 컴퓨팅, 이동 컴퓨팅, 이동 에이전트, 시스템 보안, 운영체제, 내장형 시스템 등 